\title{
MICROORGANISMS IN KHOA, THE BASE OF INDIAN SWEETS, AND THEIR
} IMPACT ON PUBLIC HEALTH

\section{CHOUDHURY L ${ }^{1 *}$, ROY $\mathrm{S}^{2}$ AND CHAKRABARTI $\mathrm{K}^{3}$}

1: State-Aided College Teacher, Department of Microbiology, Sarsuna College (under University of Calcutta), 4/HB/A, Ho-Ch-Minh Sarani, Sarsuna Upanagari, Kolkata-700 061,

West Bengal, India

2: Assistant Professor, Department of Biotechnology, St. Xavier's College (Autonomous), 30, Mother Teresa Sarani, Kolkata-700 016, West Bengal, India

3: Retd. Reader, Department of Agricultural Chemistry and Soil Science, Institute of Agricultural Science, University of Calcutta, 35, Ballygunj Circular Road, Kolkata-700 019, West Bengal, India

*Corresponding Author: E Mail: lopamudraroy82@rediffmail.com; Telephone: +91 9831460042

Received $18^{\text {th }}$ Jan. 2020; Revised $18^{\text {th }}$ Feb. 2020; Accepted $16^{\text {th }}$ March 2020; Available online $1^{\text {st }}$ Sept. 2020 https://doi.org/10.31032/IJBPAS/2020/9.9.5171

ABSTRACT

Background: Khoa, a heat-desiccated milk product widely used as a base ingredient for the preparation of sweets in India, can be a major vehicle for the transmission of notorious foodborne pathogens. Objective: To assess the microbial contamination of khoa. Materials and methods: Twenty-six khoa samples, collected from different sweet shops in and around Kolkata, were tested for total plate counts (TPCs), TPC and confirmation of Staphylococcus aureus, coliform and fecal coliform (Escherichia coli) counts, and various other potential food-borne pathogens, besides studying the multi-drug resistance (MDR)-pattern of the $E$. coli strains isolated. Results and Discussion: TPCs ranged from 6.954 to 8.477 log colonyforming unit (cfu) $\mathrm{g}^{-1}$, whereas TPCs of Staphylococcus spp. ranged from 6.698 to $8.431 \mathrm{log}$ cfu $^{-1}$. Nine (34.61\%) of the samples harbored coagulase-positive S. aureus. The presence of coliforms was detected in all (100\%) samples, with the average count being 135.76 Most Probable Number (MPN) $\mathrm{g}^{-1}$. The presence of Escherichia coli was confirmed in twenty-two 
(84.61\%) of them. S. aureus, Salmonella spp., Shigella spp., Vibrio cholerae and $V$. parahaemolyticus were detected in fourteen (53.84\%), four (15.38\%), eleven (42.30\%), five $(19.23 \%)$ and one $(3.84 \%)$ of the samples respectively. Alarmingly, majority of the E. coli isolates displayed resistances to ampicillin (90.90\%) and tetracycline (50\%), thus turning out to be MDR. Conclusion: An apparent relationship between high TPCs, detection of coliforms, fecal coliforms and MDR-E. coli isolates, and the presence of notorious foodborne pathogens revealed severe microbial contamination of khoa produced and sold unhygienically from this part of the country.

\section{Keywords: Coliform and fecal coliform counts, food-borne pathogens, khoa, microbial contamination, multi-drug resistance, TPCs}

\section{INTRODUCTION}

Milk and milk products play an essential role in human nutrition all across the world. It is estimated that dairy products comprise at least $25 \%$ of the daily nutrition intake in man [1]. Over the millennia, traditional milk products of India have enriched the cuisine of this vast subcontinent. These products constitute a large array of tempting confections like dahi, makkhan, lassi, ghee, kheer, chhana, paneer, khoa, and different sweets like shrikhand and sandesh. Among these, sweets occupy the most important kind of desert in India, which have become synonymous with feasts, festivals and various celebrations all the year round.

Most of these sweets require khoa as the chief ingredient. Khoa is a partially dehydrated, heat-desiccated $\left(98^{0} \mathrm{C}\right.$ for 15 20 minutes) milk product that is widely used as a base ingredient for the preparation of numerous indigenous sweets like peda, burfi, gulabjamun and kalakand [2]. A good quality khoa has a white/pale yellow color, a pleasant flavor, firm structure and smooth texture [2]. It keeps well for 2-3 days in hot weather, and 4-5 days in cold weather; addition of sugar prolongs its shelf-life to 3-4 months [2]. There are three main varieties of khoa pindi, dhap and danedar, which differ in quality and price [3]. It is estimated that nearly $7 \%$ of the total milk produced in India is converted into khoa for production of sweets [4]. Today, the India is estimated to produce over 300 million $\mathrm{kg}$ of khoa, valued at a total of Rs 300 crores at the current rates [5].

Although in Kolkata, West Bengal, a majority of the population consumes a wide variety of khoa-based sweets, the foodindustry recognizes it as a 'highlyperishable food'. Its moderate to nearneutral $\mathrm{pH}$ (in the range of about 6.4-6.6), a 
high moisture-content of about $96 \%$ (water activity or, $\mathrm{a}_{\mathrm{w}}$ 0.96), a high oxidationreduction $(\mathrm{O}-\mathrm{R})$ potential $(E h)$ favouring the growth of aerobic, anaerobic and facultative microorganisms, and all the necessary nutrients in the right kind and proportions required for an effective establishment of a chemoorganotrophic microbial flora make it very susceptible to bacterial invasion and multiplication [6].

The unwanted microorganisms can reach khoa during its preparation from milk which is inadequately heated and cooled, or from poor quality of milk contaminated from various sources like infected cowudder (in case of mastitis disease of cows), animal feeds and manures. Besides, khoa may become contaminated from infected dairy-utensils and milk-contact surfaces, from unclean hands and arms of the milker or dairy-workers, as well as from air, contaminated water supplies for cleaning and production, unhygienic manufacturing units and equipments, flies and crosscontamination. So, it is very important that the product be prepared hygienically, reducing its microbial load. Besides, khoa is often prepared in large bulk, and stored at room temperature for long duration, much in advance to its use in the preparation of sweets, particularly during festive seasons. Inadequate processing before use, following such a prolonged storage, obviously deteriorates the quality of khoa.

Under sub-tropical climatic conditions, the shelf-life of khoa is 2-3 days at room temperature, and about 3 weeks under refrigerated storage conditions $[3,7]$. As in a hot and humid place like Kolkata, microbial contamination is accentuated by high ambient temperature and humidity, and as most of the times the khoa is not refrigerated post-production, its keeping quality drops drastically. Hence, contamination with enteric pathogens not only causes changes in the color, odor, taste and texture of the khoa, it can also result in outbreaks of severely-fatal gastrointestinal infections in the consumers. This is because, once contaminated, this food favors the growth of the organisms, under conditions of abuse storage, to an extent where the sheer number of their metabolites may cause disease upon ingestion of such foods. Thus, a multitude of mild to fatal health hazards like nausea and vomiting, fever, abdominal cramps, upset stomach, diarrhea and dehydration may result from the consumption of these unhygienicallyprepared khoa, often leading to morbidity and mortality.

Presently, only a few scientific reports are available on the microbiological quality of khoa. Although several studies carried out in different parts of India pointed that 
pathogenic organisms like Streptococcus spp., Lactobacillus spp., Proteus spp., Pseudomonas spp., Serratia spp., Enterobacter spp., Klebsiella spp., drugresistant fecal coliforms like Escherichia coli, including enteropathogenic E. coli (EPEC), and Bacillus cereus often contaminate khoa $[\mathbf{8}, 9]$, no investigative reports are currently available from this part of the country, as also on their contamination status by the other much more notorious food-borne pathogens of public-health significance, like Staphylococcus aureus, Salmonella spp., Shigella spp. and Vibrio spp. Also a regular monitoring of this traditional milk product is mandatory due to constantly changing climatic conditions, population structure and food habits in different parts of Kolkata and its surroundings over the years, which generally alter the usual contamination profile of khoa already studied.

Also, given that the emergence of multidrug resistant (MDR)-pathogens are on a whooping rise in this era of antibiotic overuse and misuse, it is of utmost importance that the antibiogram, indicative of the MDR-pattern of these severe khoaborne pathogens, be studied, in order to give epidemiologically significant data required by the health-sectors in both Government and Non-Government Organizations for formulating a proper course of treatment for patients suffering from khoa-mediated food-borne illnesses. So, keeping in view the above facts, the present study was designed to examine the bacterial load of khoa sold at different sweet shops in and around Kolkata, and to assess its potential as a vehicle for the transmission of microorganisms of enormous public health concern. For this purpose, total plate counts (TPCs), TPC of Staphylococcus spp. and confirmation of Staphylococcus aureus, coliform and fecal coliform (Escherichia coli) counts, and the presence of various other potential foodborne pathogens like Salmonella spp., Shigella spp., Vibrio cholerae and $V$. parahaemolyticus were ascertained, confirmed and enumerated. At the same time, the antibiogram of the E. coli isolates was also studied in order to find out their MDR-pattern. The idea behind was to get a notion of the hygiene-status of the shopvended khoa, to make the consumers aware of the dire consequences that may befall if they continue to consume contaminated khoa, to highlight that it is the right time to ensure a better hygiene-profile of khoa still prepared and sold with minimal hygiene and sanitation, and also to propose a suitable treatment-regime in case of infections caused by khoa-borne MDRpathogens. 


\section{MATERIALS AND METHODS}

Chemicals, reagents, dehydrated media, media base, supplements and antibiotics

All chemicals and reagents used in this study were purchased from Merck Specialities Private Limited, India and Sisco Research Laboratories Private Limited, India. All dehydrated media, media base, supplements, coagulase plasma (from rabbit) and the antibiotics (ampicillin, chloramphenicol, streptomycin and tetracycline) in the form of commercially-available impregnated discs were procured from HiMedia Laboratories, India.

\section{Collection of samples}

Twenty-six $100 \mathrm{~g}$ samples of khoa (Figure 1) were collected over a period of three months during summer from different arbitrarily-selected sweet shops $\left(4^{\text {th }}\right.$ March $-10^{\text {th }}$ June, 2019) in and around Kolkata, like from the North, Central, South and West Kolkata, and from the Northern, Western and South-Western suburbs of Kolkata, and each taken aseptically in a sterile, covered beaker [10]. Then they were transported in a cool-container to the laboratory for analysis within 1-2 h. While awaiting analysis, the samples were refrigerated $\left(4^{0} \mathrm{C}\right)$.

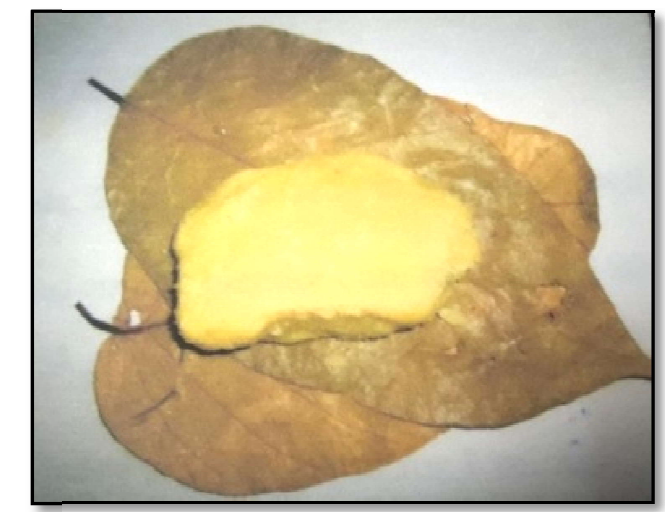

Figure 1: A khoa sample collected from a Sweet shop in Kolkata

\section{Total plate counts (TPCs)}

$20 \mathrm{~g}$ of each sample was transferred to a sterile, pre-weighed, cooled blender cup and $180 \mathrm{ml}(1: 9)$ of sterile, cool, phosphatebuffered saline $(\mathrm{pH}$ 7.2) was added to it [11]. The sample was blended at $15000 \mathrm{rpm}$ for 1 minute [11], following which subsequent 100 -fold serial dilutions $\left(10^{-3}\right.$, $10^{-5}$ and $10^{-7}$ ) of this $10^{-1}$-diluted sample were made with the same buffer. Total plate count (TPC) of each sample on Nutrient Agar (NA) medium was determined by standard Spread-plate method [11].

TPCs of Staphylococcus spp. and confirmation of Staphylococcus aureus

A $0.1 \mathrm{ml}$ aliquot of a blended and suitably diluted $\left(10^{-5}\right)$ sample was placed at the 
center of a sterile, selective Baird-Parker agar plate, spread and incubated at $35^{\circ} \mathrm{C}$ for $48 \mathrm{~h}$ [11], after which the characteristic colonies, typical of Staphylococcus spp., were identified by their characteristic growth on NA slant, routine microbiological and biochemical tests [12], and the total number of colonies in each plate counted (TPC). Alongside these tests, Staphylococcus aureus was identified by the confirmatory 'Coagulase' test [12], and the total number of such colonies in each plate counted (TPC for $S$. aureus).

\section{Coliform and fecal coliform counts}

To enumerate the coliforms by the five tubes most probable number (MPN) method (5x5) using sterile Lauryl Sulfate Tryptose Broth (LSTB) as the selective medium and each $10^{-1}$ diluted sample, following incubation at $35^{\circ} \mathrm{C}$ for $48 \mathrm{~h}$ under shaking conditions, growth (turbidity) and gas production was noted in each tube [11]. The number of coliforms present (MPN g ${ }^{-1}$ ) in the undiluted sample was then calculated with the help of a standard MPN-table. The coliform counts were then confirmed by sub-culturing all positive LSTB tubes with a standard $3 \mathrm{~mm}$ loop into tubes containing sterile, selective Brilliant Green Bile Broth (BGBB). The BGBB tubes were then incubated for $48 \mathrm{~h}$ at $35^{\circ} \mathrm{C}$ under shaking conditions, and likewise examined for growth (turbidity) and gas formation.
Fecal coliforms (E. coli) were detected by sub-culturing all positive LSTB tubes in tubes containing sterile, selective Escherichia coli (EC) broth [11]. The tubes were incubated at $45^{\circ} \mathrm{C}$ for $24 \mathrm{~h}$ under shaking conditions, examined for growth (turbidity) and gas production [11], and the number of fecal coliforms present (MPN g ${ }^{-1}$ ) in the undiluted sample was similarly calculated. One loopful from each of the positive EC tubes were streaked onto sterile, selective and differential Eosine Methylene Blue (EMB) agar plates, and incubated at $35^{\circ} \mathrm{C}$ for $24 \mathrm{~h}$ [11]. Postincubation, the characteristic colonies, typical of $E$. coli, were identified on the basis of their characteristic growth on NA slant, and routine microbiological and biochemical tests [12].

\section{Salmonella and Shigella}

$25 \mathrm{~g}$ of each sample was transferred to a sterile, pre-weighed, cooled blender cup and $225 \mathrm{ml} \mathrm{(1:9)}$ of sterile, cool, preenrichment lactose broth (LB) was added to it [11]. The sample was blended at 15000 rpm for 1 minute [11]. This seeded preenrichment broth was then incubated at $35^{\circ} \mathrm{C}$ for $24 \mathrm{~h}$ under shaking conditions [11]. A $1 \mathrm{ml}$ aliquot of this pre-enriched culture was next transferred to $9 \mathrm{ml}$ of sterile selenite-cystine enrichment broth, and incubated further at $35^{\circ} \mathrm{C}$ for $24 \mathrm{~h}$ under shaking conditions [11]. After 
incubation, one loopful of the enriched culture was streaked onto plates containing sterile, selective and differential Salmonella-Shigella (SS) agar and Hektoen Enteric Agar (HEA) [10]. All the plates were then incubated at $35^{\circ} \mathrm{C}$ for $24 \mathrm{~h} \mathrm{[10]}$. Colonies having characteristics typical of Salmonella spp. and Shigella spp. were then identified on the basis of their characteristic growth on NA slant, and routine microbiological and biochemical tests [11], and the total number of their colonies in each plate counted.

\section{Vibrio cholerae and $V$. parahaemolyticus}

$25 \mathrm{~g}$ of each sample was transferred to a sterile, pre-weighed, cooled blender cup and $225 \mathrm{ml}$ (1:9) of sterile, cool, alkaline peptone water (PW) as the enrichment broth for $V$. cholerae was added to it [11]. The sample was blended at $15000 \mathrm{rpm}$ for 1 minute [11]. This seeded broth was then incubated at $35^{\circ} \mathrm{C}$ for $8 \mathrm{~h}$ under shaking conditions [11]. After incubation, one loopful from this PW culture was streaked onto a sterile, selective and differential Thiosulphate Citrate Bile Salts Sucrose (TCBS) agar plate [10]. Following incubation at $35^{\circ} \mathrm{C}$ for $24 \mathrm{~h}$, colonies characteristic of Vibrio cholerae were subcultured on sterile $\mathrm{T}_{1} \mathrm{~N}_{1}$ agar slants and the slants incubated overnight at $35^{\circ} \mathrm{C}$ [10].Confirmation of Vibrio cholerae was done on the basis of their characteristic growth on NA slant, and routine microbiological and biochemical tests [11], and the total number of colonies in each plate counted. Glucose salt teepol broth and TCBS agar media were respectively used as enrichment, and selective and differential medium for the detection of Vibrio parahaemolyticus [11]. Its confirmation was done by growth-pattern observation on NA slant, and routine microbiological and biochemical tests were carried out similarly as done for Vibrio cholerae [11], and the total number of colonies in each plate counted.

\section{Antibiotic sensitivity test and determination of MDR-pattern}

The antibiotic sensitivity test for the E. coli isolates was performed according to the standard Kirby-Bauer Disc Diffusion method, and as per the recommendations of the Clinical Laboratory Standards Institute (CLSI) [13, 14]. The antibioticimpregnated discs used were those of

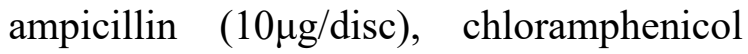
$(30 \mu \mathrm{g} / \mathrm{disc})$, streptomycin $(25 \mu \mathrm{g} / \mathrm{disc})$ and tetracycline $(30 \mu \mathrm{g} / \mathrm{disc})$. After incubation at $37^{0} \mathrm{C}$ for $24 \mathrm{~h}$, the diameter of the zones of growth inhibition were measured in $\mathrm{mm}$, and the relative susceptibilities of the different isolates to the different antibiotics used were determined with the help of the Kirby-Bauer standard zone-size data 
interpretative chart to ascertain the MDRpattern [15].

\section{Statistical analysis}

All results were expressed as mean \pm SEM (Standard Error of Mean) for individual experiment. Each experiment was performed three times $(n=3)$, and the mean value from all set of those experiments was presented. Student's t-test was performed as applicable in each case, and the values were found to be significant at $5 \%$ probability level.

\section{RESULTS AND DISCUSSION}

Confirmation of Staphylococcus spp., including Staphylococcus aureus

Small to medium (4-6 $\mathrm{mm})$, discrete, elevated, dark-gray to black colonies, many with an opaque zone of precipitation appeared on the Baird-Parker agar plates, indicating the presence of Staphylococcus spp. (Figure 2a). Dark-gray to black colonies with an opaque zone of precipitation indicated $S$. aureus. It was confirmed by its pale-yellow, translucent growth on a NA slant, purplish-violet (Gram-positive), medium cocci in a grapelike-cluster appearance after Gram-staining, and typical results in biochemical tests (Figure 2b, Table 1).

Confirmation of coliforms, including fecal coliforms ( $E$. coli)

Small (2-3 mm), discrete, flat, smooth, nonmucoid, nucleated (black centre), purple colonies, most with a very prominent greenish metallic sheen typical of fecal coliform (E. coli) (Figure 3), were isolated from the EMB-agar plates. E. coli was confirmed by its pale-white, translucent growth on a NA slant, reddish-pink (Gramnegative), short, thin, isolated rod appearance after Gram-staining, and typical results in biochemical tests (Table 2).

\section{Confirmation of Salmonella and Shigella}

Characteristic colonies, typical of Salmonella spp. and Shigella spp. were isolated from the SS agar-plates and HEAplates. Small to medium $(2-4 \mathrm{~mm}$ in diameter), discrete, slightly-raised, smooth, translucent colonies, most with a very prominent black centre, were observed on the SS agar-plates (Figure 4a), whereas small to medium (2-4 $\mathrm{mm}$ in diameter), discrete, slightly-raised, smooth, translucent green-colored colonies, most with a very prominent black centre, were observed on the HEA-plates (Figure 4b), both suggesting the presence of Salmonella spp. On the other hand, small, medium and large (2-6 $\mathrm{mm}$ in diameter), discrete, slightly-raised, smooth, translucent colonies were observed on the SS agarplates (Figure 5a), whereas small, medium and large (2-6 $\mathrm{mm}$ in diameter), discrete, slightly-raised, smooth, translucent greencolored colonies were observed on the HEA-plates (Figure 5b), both suggesting 
the presence of Shigella spp. Both Salmonella spp. and Shigella spp. were confirmed by their characteristic palewhite, translucent growth on a NA slant, reddish-pink (Gram-negative), short, thin, isolated rod appearance after Gramstaining, and typical results in biochemical tests (Table 3).

\section{Counts and confirmation of Vibrio cholerae and $V$. parahemolyticus}

Small to medium (3-5 mm), discrete, slightly flattened, smooth, yellow colored colonies with opaque centres and translucent peripheries appeared on the TCBS-agar plates, indicating the presence of Vibrio cholerae, which fermented sucrose to produce a yellow color that later changed to green upon prolonged incubation (Figure 6a). Small to medium, discrete, slightly flattened, smooth, colorless colonies with green centres and translucent peripheries appeared on the TCBS-agar plates, indicating the presence of $V$. parahaemolyticus (Figure 6b). Both $V$. cholerae and $V$. parahaemolyticus were confirmed by their pale-white, translucent growth on a NA slant, reddish-pink (Gramnegative), short, isolated, curved ('comma') rod appearance after Gram-staining, and typical results in biochemical tests (Table 4).

Total plate counts (TPCs), TPCs of Staphylococcus spp. (including
Staphylococcus aureus), coliform and fecal coliform ( $E$. coli) counts, and counts of selected food-borne pathogens

In the present study, a total of twenty-six samples of khoa were examined to determine their bacterial load. The total plate counts (TPCs) (Figure 7), TPCs of Staphylococcus spp., along with coliform and fecal coliform (E. coli) counts observed in these khoa samples are presented in Table 6. Being a partially dehydrated, heatdesiccated $\left(98^{0} \mathrm{C}\right.$ for $15-20$ minutes) whole milk product, it is expected that the microbial count of the finished product should be low. However, the observations of this study presented an alarmingly huge microbial contamination picture. Such high average bacterial counts, be it the TPCs (7.959 log cfu g ${ }^{-1}$ ), TPCs of Staphylococcus spp. (7.677 $\log \mathrm{cfu} \mathrm{g}^{-1}$ ) or the counts of coliforms (135.76 MPN $\mathrm{g}^{-1}$ ) and fecal coliforms (123.95 MPN g ${ }^{-1}$ ) (Table 5), in khoa, are highly undesirable, since it highlights the most unhygienic conditions of its preparation and storage.

Further detailed analysis reveals that 1 (3.84\%), $11(42.30 \%)$ and $14(53.84 \%)$ among the 26 khoa samples had TPCs (log cfu $^{-1}$ ) $<7,7-8$ and $>8$, respectively (Table 6). All the 26 khoa samples examined $(100 \%)$ showed the presence of Staphylococcus spp. Among them, 6 (23.07\%), 9 (34.61\%) and 11 (42.30\%) had 
TPCs (log cfu g $\left.{ }^{-1}\right)$ of Staphylococcus spp. $<7,7-8$ and $>8$, respectively (Table 7 ). Coagulase-positive $S$. aureus were detected in $1(16.66 \%)$ out of 6 samples, $4(44.44 \%)$ out of 9 samples and $9(81.81 \%)$ out of 11 samples having TPCs (log cfu $\left.\mathrm{g}^{-1}\right)$ of Staphylococcus spp. $<7,7-8$ and $>8$, respectively (Table 6). Coliforms and fecal coliforms (E. coli) were detected in 26 $(100 \%)$ and 22 (84.61\%) samples, respectively. Presence of E. coli, a recognized indicator of fecal contamination, was confirmed in all of the 22 fecal coliform-positive samples (100\%) (Table 6). The number of samples positive for fecal coliforms increased with increase in TPCs, as shown in Table 7, from 8 $(72.72 \%)$ in cases of samples with aerobic TPCs between 7-8 $\log \mathrm{cfu} \mathrm{g}^{-1}$ to $14(100 \%)$ in cases of samples with aerobic TPCs $>8$ $\log \mathrm{cfu} \mathrm{g}^{-1}$. Furthermore, among the 26 khoa samples examined, Salmonella spp. and Shigella spp. were detected in 4 samples $(15.38 \%)$ and 11 samples $(42.30 \%)$ respectively, out of which 4 $(100 \%)$ and $4(36.36 \%)$ showed aerobic plate counts $>8 \log \mathrm{cfu} \mathrm{g}^{-1}$ (Table 6). Also, among the 26 khoa samples analysed, Vibrio cholerae and $V$. parahemolyticus were detected in 5 samples (19.23\%) and 1 sample $(3.84 \%)$ respectively, out of which $4(80 \%)$ and $1(100 \%)$ showed aerobic plate counts $>8 \log$ cfu g $^{-1}$ (Table 6).
These data indicate that Staphylococcus spp. was the prominent organism among all the six selected food-borne pathogens isolated from the khoa samples, being recovered from all of them (100\%). $42.30 \%$ of the samples had TPCs of Staphylococcus spp. $>8 \log \mathrm{cfu}^{-1}$, out of which $81.81 \%$ were detected to contain coagulase-positive S. aureus with TPCs $>8 \log \mathrm{cfu} \mathrm{g}^{-1}$. Most alarmingly, a large number of people in India fall victims of food-borne illnesses caused by toxins produced by $S$. aureus ingested with khoa, like Staphylococcal Enterotoxicosis via production of its heat stable enterotoxin. Cows excrete Staphylococci from their udder, but these bacteria are heat-sensitive and should be destroyed during the preparation of khoa. Therefore, its presence in the positive samples indicates inadequate Pasteurization, or that it is acquired from the contaminated hands of khoa-makers and sellers.

Coliforms are generally heat-labile, and their isolation from all the samples indicates post-processing contamination. In fact, the enumeration of coliforms, fecal coliforms (E. coli) in food products is employed generally as a reliable sanitation index of water, food, milk and dairy products for predicting unhygienic conditions during production and processing. Therefore the presence of these 
organisms in food beyond the limit of tolerance generally indicates that the food in question has been fecally-contaminated with human and/or animal wastes, and exposed to conditions that might as well introduce or allow proliferation of enteric pathogens. In the present study, recovery of E. coli strains from almost all the samples of khoa $(84.62 \%)$ thus indicates the possible presence of notorious enteropathogenic and/or enterotoxigenic pathogenic bacteria in it, like Salmonella spp., Shigella spp. and Vibrio spp., which could be a fatal public health hazard, being able to cause severe gastroenteritis and food-poisoning in infants and young children in particular. In this study, 100\% of all the khoa samples analysed to have TPCs of coliforms $>8 \log \mathrm{cfu} \mathrm{g}^{-1}$ were also found to harbor the fecal coliforms ( $E$. coli). Pathogenic strains of E. coli (in particular E. coli O157:H7) may cause cholecystitis, bacteremia, UTIs, Traveller's Diarrhea, neonatal meningitis and pneumonia. It is not quite astonishing that fecal-coliforms were detected, considering the unhygienic conditions behind the preparation of these foodstuffs, and contaminated water used for washing of the utensils or production of khoa.

Although the presence of other dreadful pathogens such as Salmonella spp. and Shigella spp. were found to be relatively less in this study $(15.38 \%$ and $42.30 \%$ respectively), the mere presence of these pathogens suggests that there is a potential risk of spread of typhoid fever (caused by S. enterica Serotype typhi), gastroenteritis and enteric fever (Salmonellosis) (caused by $S$. enterica Serotype Typhimurium), and Shigellosis among the community. Alarmingly $100 \%$ and $36.36 \%$ khoa samples showed the presence of Salmonella spp. and Shigella spp. with TPCs $>8 \log$ cfu $\mathrm{g}^{-1}$. Presence of Vibrio spp., bacteria that causes cholera (caused by $V$. cholerae) and gastro-enteritis (Vibriosis, caused by $V$. parahaemolyticus) were also noted in $19.23 \%$ and $3.84 \%$ of the khoa samples respectively, out of which $80 \%$ and $100 \%$ khoa samples indicated the presence of $V$. cholerae and $V$. parahaemolyticus with TPCs $>8 \log \mathrm{cfu} \mathrm{g}^{-1}$. The presence of these pathogens in the analysed samples thus points out to their fecal contamination by excreta of humans and/or animals, indicating less-than-ideal maintenance of hygiene.

\section{Antibiotic sensitivity test and determination of MDR-pattern}

The present study also provided an insight into the MDR-pattern (Figure 8) of the $E$. coli isolates found in $22(84.61 \%)$ of a total of 26 khoa samples tested. 20 out of 22 of the E. coli isolates $(90.90 \%)$ displayed an enormous resistance to ampicillin, 11 out of 
22 of the E. coli isolates (50\%) showed resistance to tetracycline, and 1 out of 22 of the $E$. coli isolates $(4.54 \%)$ showed resistance to streptomycin (Table 7, Figure 9). Thus, many of the E. coli isolates of this study turned out to be MDR strains against at least two much used antibiotics ampicillin and tetracycline, whereas one displayed resistance against streptomycin. Therefore, the above data points to the fact that the drugs of choice for treating severe forms of diarrhea caused by such MDRpathogenic strains of E. coli would be preferably chloramphenicol $\quad(100 \%$

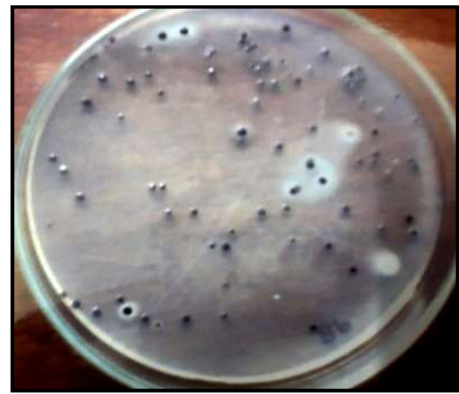

(a)

sensitivity) and streptomycin (95.45\% sensitivity), whereas drugs like ampicillin and tetracycline must never be recommended as therapeutics (Table 7, Figure 9). This work thus provides knowledge about the appropriate treatmentregime that can be followed for patients suffering from such MDR-E. coli-mediated diarrhea, helping in their accurate and timely cure. Thus, a proper waste and drug management practice will not only take care of the public health, but will also help reduce the increasing incidences of multidrug resistance.

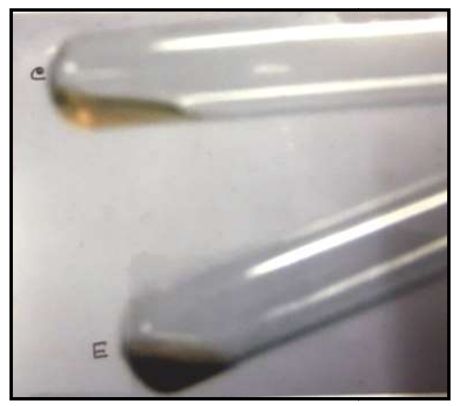

(b)

Figure 2: (a) Representative colonies of Staphylococcus spp. (including $S$. aureus) on a Baird-Parker agar plate $\left(10^{-5}\right.$ dilution); (b) Coagulase-positive (E) Staphylococcus aureus and coagulase-negative (C) Staphylococcus sp. The picture represents the results of three independent experiments with identical results $(n=3)$

Table 1: Results of the standard biochemical tests for Staphylococcus aureus

\begin{tabular}{|c|c|c|c|c|c|c|c|c|c|c|}
\hline \multicolumn{4}{|c|}{$\underline{z}$} & \multirow[b]{2}{*}{ 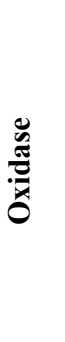 } & \multirow[b]{2}{*}{ 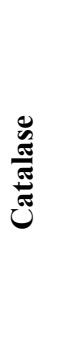 } & \multirow[b]{2}{*}{ 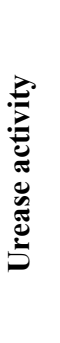 } & \multirow{2}{*}{ 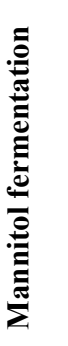 } & \multirow{2}{*}{ 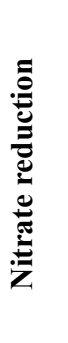 } & \multirow{2}{*}{ 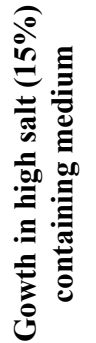 } & \multirow[b]{2}{*}{ 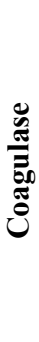 } \\
\hline$\stackrel{\vec{\Xi}}{\bar{\pi}}$ & $\sum_{0}^{\underline{Z}}$ & ֶี & 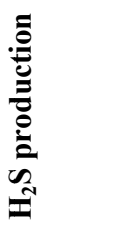 & & & & & & & \\
\hline $\begin{array}{l}\text { Yellow } \\
\text { (acidic) }\end{array}$ & $\begin{array}{l}\text { Yellow } \\
\text { (acidic) }\end{array}$ & \pm & + & - & + & + & + & + & + & + \\
\hline
\end{tabular}




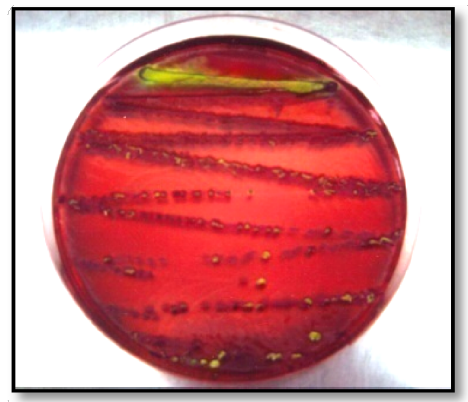

Figure 3: Colonies typical of fecal-coliform (E. coli) on an EMB agar plate. The picture represents the results of three independent experiments with identical results $(n=3)$

Table 2: Results of the standard biochemical tests for fecal coliforms $(E$. coli)

\begin{tabular}{|c|c|c|c|c|c|c|c|c|c|c|}
\hline \multirow{2}{*}{ 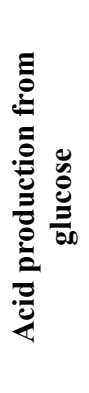 } & \multicolumn{4}{|c|}{$\sum_{\sum}^{\circlearrowright}$} & \multirow{2}{*}{ 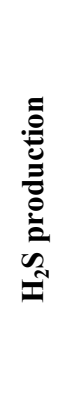 } & \multirow{2}{*}{ 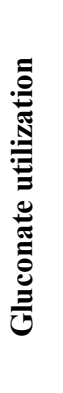 } & \multirow{2}{*}{ 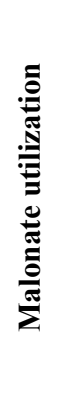 } & \multirow{2}{*}{ 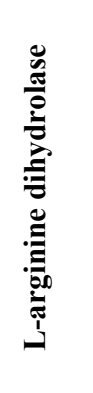 } & \multirow{2}{*}{ 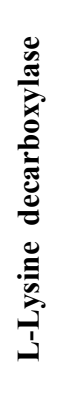 } & \multirow{2}{*}{ 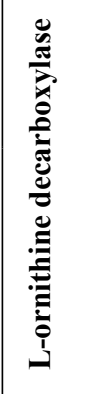 } \\
\hline & 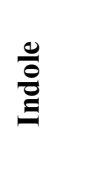 & 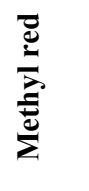 & 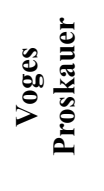 & 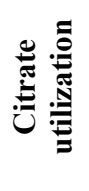 & & & & & & \\
\hline+ & + & + & - & - & - & + & - & \pm & + & \pm \\
\hline
\end{tabular}

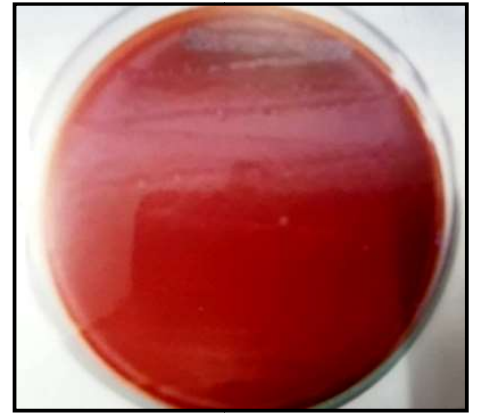

(a)

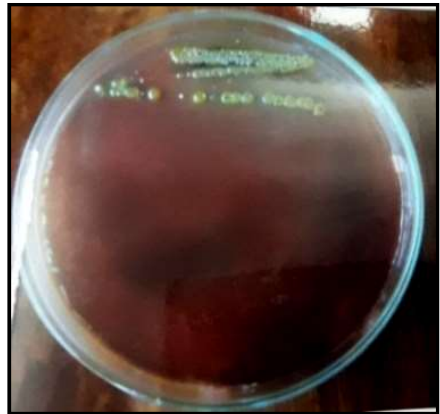

(b)

Fig. 4: Colonies typical of Salmonella spp. on (a) SS agar plate and (b) HEA plate. The picture represents the results of three independent experiments with identical results $(n=3)$

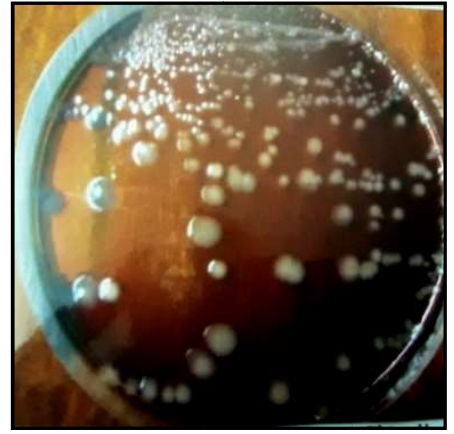

(a)

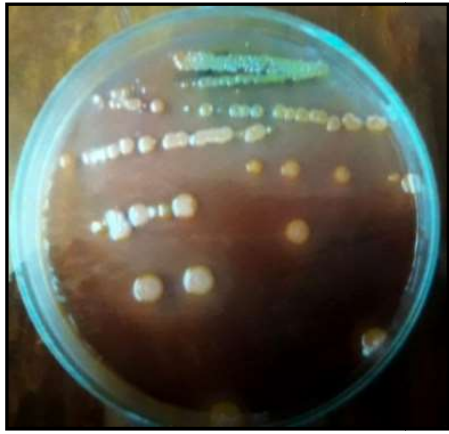

(b)

Fig. 5: Colonies typical of Shigella spp. on (a) SS agar plate and (b) HEA plate. The picture represents the results of three independent experiments with identical results $(n=3)$ 
Table 3: Results of the standard biochemical tests for Salmonella spp. and Shigella spp.

\begin{tabular}{|c|c|c|c|c|c|c|c|c|c|c|c|c|}
\hline \multirow{2}{*}{ 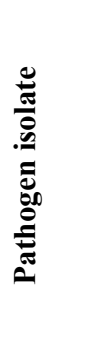 } & \multirow{2}{*}{ 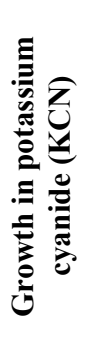 } & \multirow{2}{*}{ 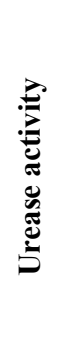 } & \multicolumn{4}{|c|}{$\bar{\omega}$} & $\stackrel{\rho}{\sum}$ & \multicolumn{4}{|c|}{$\Xi$} & \multirow{2}{*}{ 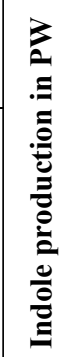 } \\
\hline & & & 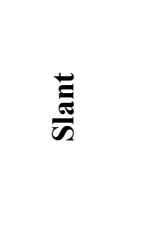 & 音 & తే & $\stackrel{n}{ \pm}$ & 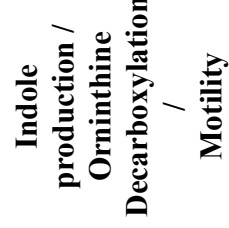 & $\frac{\vec{E}}{\omega}$ & 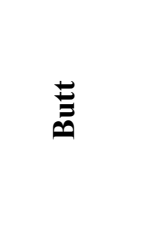 & తే & $\stackrel{n}{=}$ & \\
\hline 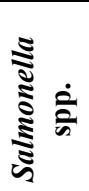 & - & - & $\begin{array}{c}\text { purple } \\
\text { (alkaline) }\end{array}$ & $\begin{array}{l}\text { Yellow } \\
\text { (acidic) }\end{array}$ & + & + & $-1+1+$ & $\begin{array}{c}\begin{array}{c}\text { Purple } \\
\text { (alkaline) }\end{array}\end{array}$ & $\begin{array}{c}\text { Purple } \\
\text { (alkaline) }\end{array}$ & + & + & - \\
\hline 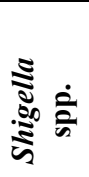 & - & - & $\begin{array}{c}\text { purple } \\
\text { (alkaline) }\end{array}$ & $\begin{array}{l}\text { Yellow } \\
\text { (acidic) }\end{array}$ & - & - & $\pm / \pm /-$ & $\begin{array}{c}\text { Purple } \\
\text { (alkaline) }\end{array}$ & $\begin{array}{l}\text { Yellow } \\
\text { (acidic) }\end{array}$ & - & - & - \\
\hline
\end{tabular}
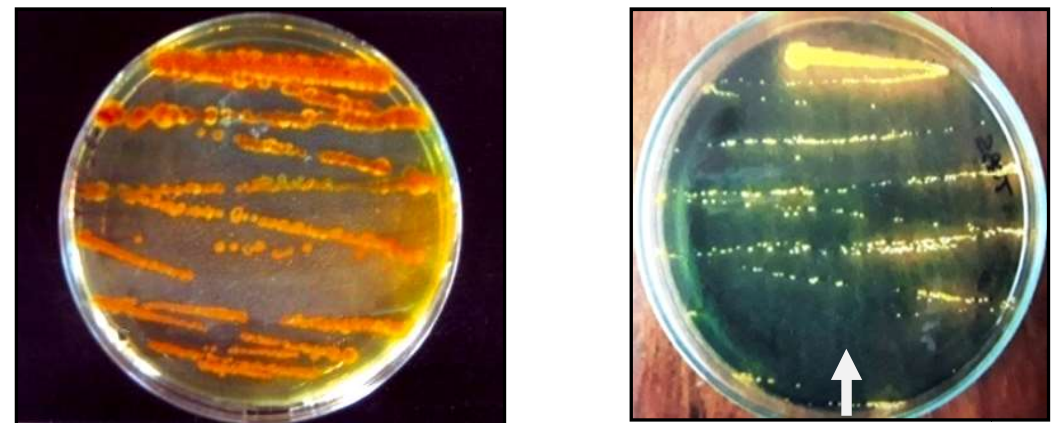

Fig. 6: Colonies typical of (a) Vibrio cholerae and (b) Vibrio parahaemolyticus (indicated) on TCBS agar plate. The picture represents the results of three independent experiments with identical results $(n=3)$

Table 4: Results of the standard biochemical tests for Vibrio cholerae and V.parahaemolyticus

\begin{tabular}{|c|c|c|c|c|c|c|c|c|c|c|c|}
\hline \multirow{2}{*}{ 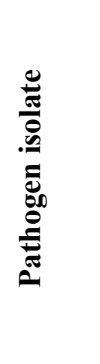 } & \multicolumn{4}{|c|}{$\mathbb{1}$} & \multirow{2}{*}{ 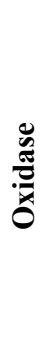 } & \multirow{2}{*}{ 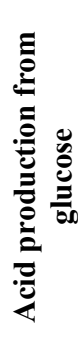 } & \multirow{2}{*}{ 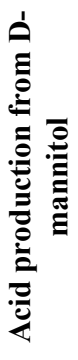 } & \multirow{2}{*}{ 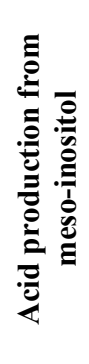 } & \multirow{2}{*}{ 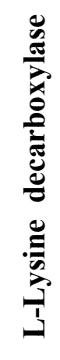 } & \multirow{2}{*}{ 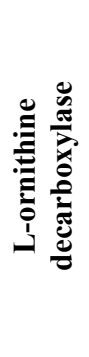 } & \multirow{2}{*}{ 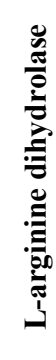 } \\
\hline & $\frac{\vec{E}}{\omega}$ & 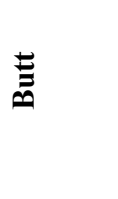 & שี & 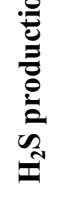 & & & & & & & \\
\hline 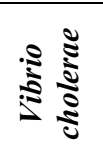 & $\begin{array}{c}\text { Red } \\
\text { (alkaline) }\end{array}$ & $\begin{array}{c}\text { yellow } \\
\text { (acidic) }\end{array}$ & - & - & + & + & + & - & + & + & - \\
\hline 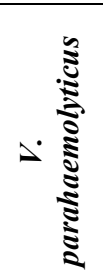 & $\begin{array}{c}\text { Red } \\
\text { (alkaline) }\end{array}$ & $\begin{array}{l}\text { yellow } \\
\text { (acidic) }\end{array}$ & - & - & + & + & + & \pm & + & + & - \\
\hline
\end{tabular}




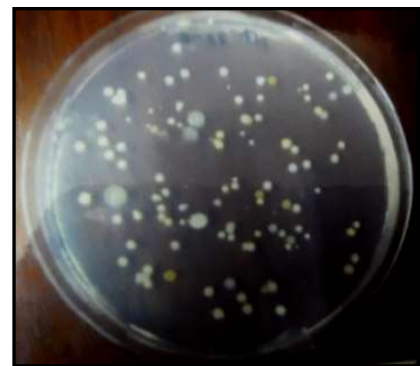

Figure 7: Representative bacterial colonies of a khoa sample on a NA plate

$\left(10^{-5}\right.$ dilution). The picture represents the results of three independent experiments with identical results $(\mathrm{n}=3)$

Table 5: Microbial counts* of 26 khoa samples

\begin{tabular}{|c|c|c|c|}
\hline Parameter & Minimum & Maximum & Average \\
\hline TPCs $\left(\log\right.$ cfu g $\left.{ }^{-1}\right)$ & 6.954 & 8.477 & 7.959 \\
\hline $\begin{array}{c}\text { TPCs of Staphylococcus spp. (log } \\
\left.\text { cfu } \mathrm{g}^{-1}\right)\end{array}$ & 6.698 & 8.431 & 7.677 \\
\hline $\begin{array}{c}\text { Coliform count } \\
\left(\mathrm{MPN} \mathrm{g}^{-1}\right)\end{array}$ & 2 & 240 & 135.76 \\
\hline Fecal coliform count $\left(\mathrm{MPN}^{-1}\right)$ & 1.3 & 240 & 123.95 \\
\hline
\end{tabular}

* Each value represents the average of 3 determinations $(n=3)$

Table 6: Relationship between TPCs* and the presence of Staphylococcus spp. (including coagulase-positive Staphylococcus aureus), coliforms, fecal coliforms (E. coli) and selected food-borne pathogens in 26 samples of khoa

\begin{tabular}{|c|c|c|c|c|c|c|c|c|c|}
\hline \multirow{2}{*}{$\begin{array}{c}\text { TPC } \\
(\log \\
\left.\text { cfu }^{-1}\right)\end{array}$} & \multirow{2}{*}{$\begin{array}{l}\text { Number } \\
\text { Of } \\
\text { samples } \\
\text { within } \\
\text { the } \\
\text { range }\end{array}$} & \multirow[b]{2}{*}{ 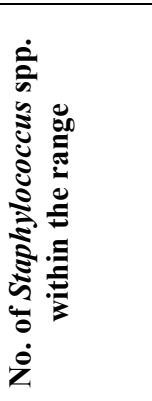 } & \multicolumn{7}{|c|}{ Number of samples positive for } \\
\hline & & & 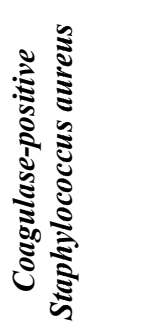 & $\stackrel{0}{0}$ & 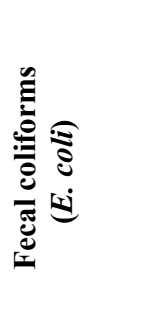 & 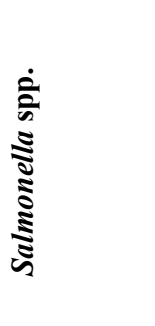 & 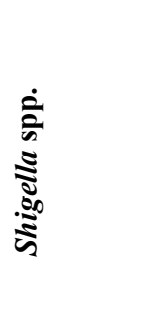 & $\begin{array}{c}5 \\
0 \\
0 \\
0 \\
0 \\
5 \\
2 \\
2\end{array}$ & 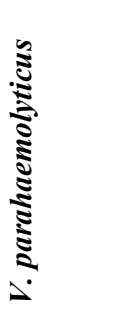 \\
\hline$<7$ & $\begin{array}{c}1 \\
(3.84 \%) \\
\end{array}$ & $\begin{array}{c}6 \\
(23.07 \%)\end{array}$ & $\begin{array}{c}1 \\
(16.66 \%)\end{array}$ & $\begin{array}{c}1 \\
(100 \%)\end{array}$ & N.D. & N.D. & N.D. & N.D. & N.D. \\
\hline $7-8$ & $\begin{array}{c}11 \\
(42.30 \%)\end{array}$ & $\begin{array}{c}9 \\
(34.61 \%)\end{array}$ & $\begin{array}{c}4 \\
(44.44 \%) \\
\end{array}$ & $\begin{array}{c}11 \\
(100 \%)\end{array}$ & $\begin{array}{c}8 \\
(72.72 \%)\end{array}$ & N.D. & $\begin{array}{c}7 \\
(63.63 \%)\end{array}$ & $\begin{array}{c}1 \\
(9.09 \%)\end{array}$ & N.D. \\
\hline$>8$ & $\begin{array}{c}14 \\
(53.84 \%)\end{array}$ & $\begin{array}{c}11 \\
(42.30 \%)\end{array}$ & $\begin{array}{c}9 \\
(81.81 \%)\end{array}$ & $\begin{array}{c}14 \\
(100 \%)\end{array}$ & $\begin{array}{c}14 \\
(100 \%)\end{array}$ & $\begin{array}{c}4 \\
(28.57 \%)\end{array}$ & $\begin{array}{c}4 \\
(28.57 \%)\end{array}$ & $\begin{array}{c}4 \\
(28.57 \%)\end{array}$ & $\begin{array}{c}1 \\
(7.14 \%)\end{array}$ \\
\hline
\end{tabular}

[N.D. - Not detected in any sample; values in parentheses indicate percent positive for Staphylococcus aureus, coliforms, fecal coliforms $(E$. coli $)$ and selected food-borne pathogens of the number of samples of the particular range of TPC; *each value represents the average of 3 determinations $(n=3)$.] 


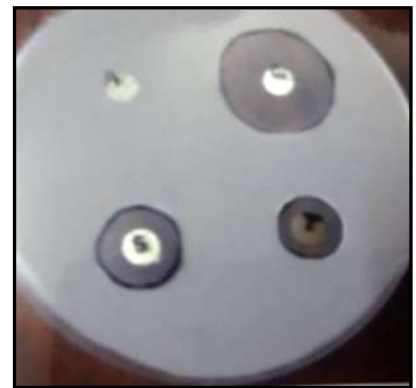

Figure 8: Results of antibiotic sensitivity test for determination of MDR-pattern of the $E$. coli isolates on NA plate. The picture represents the results of three independent experiments with identical results $(n=3)$

Table 7: Percentage of Sensitive (S) / Resistant (R) E. coli strains against the different antibiotics used

\begin{tabular}{|c|c|c|c|c|}
\hline Antibiotic-impregnated discs used & $\begin{array}{c}\text { Total number } \\
\text { of sensitive } \\
\text { isolates (a) }\end{array}$ & $\begin{array}{l}\text { \% of Sensitivity } \\
\quad(a / 22 \times 100)\end{array}$ & $\begin{array}{l}\text { Total number of } \\
\text { resistant isolates } \\
\text { (b) }\end{array}$ & $\begin{array}{c}\% \text { of } \\
\text { Resistance } \\
(\mathbf{b} / 22 \times 100)\end{array}$ \\
\hline Ampicillin $(10 \mu g$ /disc $)$ & 2 & 9.09 & 20 & 90.90 \\
\hline Chloramphenicol (30 $\mu \mathrm{g} / \mathrm{disc})$ & 22 & 100 & $\mathbf{0}$ & $\mathbf{0}$ \\
\hline Streptomycin $(25 \mu \mathrm{g} / \mathrm{disc})$ & 21 & 95.45 & 1 & 4.54 \\
\hline Tetracycline $(30 \mu \mathrm{g} /$ disc) & 11 & $\mathbf{5 0}$ & 11 & $\mathbf{5 0}$ \\
\hline
\end{tabular}

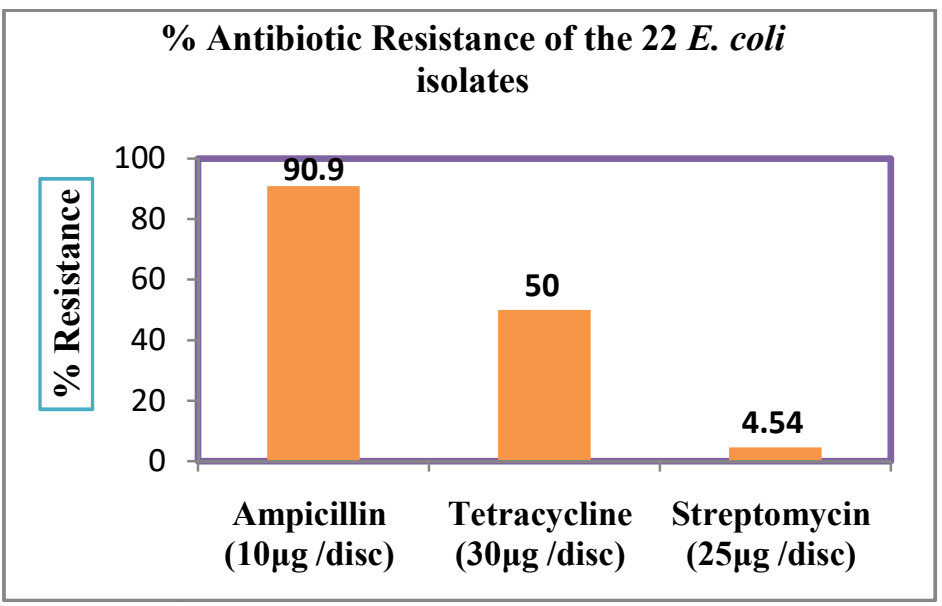

Figure 9: Graphical representation of \% Antibiotic Resistance of the 22 E. coli isolates

\section{CONCLUSION}

The results of the present study revealed that problem of microbial contamination of khoa sold from the sweet shops exists in and around the city of Kolkata, as a heavy bacterial load is found in nearly all samples, including potentially harmful food-borne pathogens, and that now it is absolutely mandatory to improve their microbiological quality from the public health point of view. As contamination of khoa by pathogenic bacteria could be an important factor of gastro-intestinal infections, it would be wise if the possible sources of such contamination can be traced down, and checked.

It is of immediate necessity that the microbiological quality of khoa be improved for public health protection. For this, an immediate improvement of the prevailing sanitary practices must be performed. A regular sterilization of dairy equipment, washing of utensils, milker's hands, udders, eradication of diseased 
animals, and a proper Pasteurization or boiling of milk are required before collection and distribution for khoamaking.

Since all these sweet-manufacturers and sellers have come to be accepted in Kolkata and its adjoining areas, in future, the health authorities may look into if they can be trained suitably in the relevant hygienic practices.

Work should also be undertaken to determine if khoa supports the growth of other food-borne pathogens, so that the conditions of storage can be designed accordingly to limit how long the manufacturers can store the product after preparing.

Also this work would epidemiologically be quite informative to the health-care officials, both from the Government and Non-Government sectors, which would ask them to restrict prescribing the most common medicines like ampicillin and tetracycline in cases of MDR E. colimediated food poisoning, and either advocate other antibiotics commercially available in the market like chloramphenicol and streptomycin, or formulate newer strategies to combat the MDR-pathogens. This hopefully would help curb the number of swiftly rising cases of multi-drug resistance, at least in this part of the country.
In future, the entire study should be repeated, as the microbial contamination profile of khoa and the MDR-patterns of the khoa-borne pathogens may tend to alter with changing socio-economicgeographical conditions of the place of study.

\section{ACKNOWLEDGEMENT}

The authors wish to express their thankfulness to Dr. A. K. Guha, Retd. Senior Professor, Department of Biological Chemistry, IACS, Kolkata and Dr. Chandan Kumar Choudhury, Kolkata.

\section{REFERENCES}

[1] Bureau of Indian Standards, Hand Book of Food Analysis, XI: Dairy Products, 21, Bureau of Indian Standards, New Delhi, 1981.

[2] Patel AA and De S, Production and storage of dried khoa, Indian Dairyman, 1977; 31(2): 79-83.

[3] Rajorhia GS, Opportunities in production and marketing of khoa and its packaging, Proc. XXXI, Dairy Industry Conference, Mumbai, 2002, p.51-57.

[4] Kurian K, Indigenous Milk Products of India, Present and Future Market Share, Indian Dairyman, 1991; 43: 106.

[5] http://www.agricultureinindia.net/da iry-science/khoa/khoa-mawa-introlclassification-composition-storage- 
and-uses-dairy-technology/20384.

Accessed 4th April, 2020.

[6] Frazier WC and Westhoff DC, Food Microbiology, $4^{\text {th }}$ Ed., Tata Mc Graw- Hill Publishing Company Limited, New Delhi, 1995, p.3-15, p.196-9.

[7] Kumar $G$ and Srinivasan MR, Effect of selected packaging materials and storage on the microbiological quality of khoa, Indian Journal of Dairy Science, 1983; 36(5): 172-7.

[8] Gill JPS, Joshi DV and Kwatra MS, Qualitative bacteriological survey of milk and milk products with special reference to Staphylococcus aureus, Indian Journal of Dairy Science, 1994;47:680.

[9] Mandokhot VV and Garg SR, Market quality of khoa, burfi and pera: A critical review, Journal of Food Science and Technology, 1986; 22: 299.

[10] Mukhopadhyay R, Mitra A, Roy R and Guha AK, An evaluation of street-vended sliced papaya (Carica papaya) for bacteria and indicator micro-organisms of public health significance, Food Microbiology, 2002; 19: 663-7.

[11] American Public Health Association (APHA), Compendium of methods for the microbiological examination of foods, American Public Health Association (APHA), Vanderzant $\mathrm{C}$ and. Splittstoesser DF (Ed.s), Washington DC, 1992.

[12] Barrow GI and Feltham RKA (Eds), Cowan and Steel's Manual for the Identification of Medicinal Bacteria, $3^{\text {rd }}$ Ed., Cambridge University Press, Cambridge, 1993.

[13] http://shsmanual.ucsc.edu/policy/k irby-bauer-antibiotic-sensitivity.

Accessed 4th April, 2020.

[14] Clinical Laboratory Standards Institute, Performance standards for antimicrobial disk susceptibility tests; Approved standard, 9th Ed., CLSI document M2-A9, 26:1, Clinical Laboratory Standards Institute, Wayne, PA, 2006.

[15] https://www.asm.org/getattachmen t/2594ce26-bd44-47f6-82870657aa9185ad/Kirby-Bauer-DiskDiffusion-Susceptibility-TestProtocol-pdf.pdf. Accessed $4^{\text {th }}$ April, 2020. 